\title{
The Relationship Between Geriatric Derpession and Perceived Social Support in Elderly: A Field Study
}

\author{
Yaşlılarda Algılanan Sosyal Desteğin Geriatrik Depresyon ile İlişkisi: Bir \\ Saha Çalışması
}

Erdem Türkseven ${ }^{l}$, Can Öner ${ }^{l}$, Engin Ersin Şimşek ${ }^{l}$

\begin{abstract}
Introduction: Geriatric depression is an important public health problem. It is reported that the increae of the perceived social support reduces depressive symptoms in elderly. The aim of this study was to investigate the relationship between perceived social support and geriatric depression. Method: 383 old people living in the community was included to this cross-sectional study. The study data were collected by face to face interview technique after obtaining the necessary permissions from the researchers. Bed-ridden participants, participants with dementia, and anti depressive drug users were excluded from the study. The participants were asked questions about the sociodemographic, economic and health status of the participants. The perceived social support of the participants was evaluated with the Multidimensional Social Support Scale (MPSS) and depression was assessed with the Geriatric Depression Scale (GDS). Data were analyzed with SPSS 21.0 package program. Results: $52,2 \%(\mathrm{n}=200)$ of the participants were female. The mean age of male and female participants was $73.1 \pm 6.2$ and72,6 $\pm 6,4$ years respectvely. The mean Geriatric Depression Scale score of the participants was $3.3 \pm 3.1$. There was a weak positive correlation between geriatric depression score and age $(\mathrm{R}=0.011 ; \mathrm{r}=0.108 ; \mathrm{p}=0.034)$. In terms of gender, depression is significantly higher in women. The mean MPSS scores of the participants were $4.7 \pm 1.55$ points. With this score, 9.6\% ( $\mathrm{n}=37$ ) of the participants had low social support. Geriatric Depression Scale scores are negatively and negatively correlated with each subscale scores of the MPSS. $(p=0.003$ and $p=0.021)$. Conclusion: The frequency of depression in elderly individuals is already high. For this reason, it is necessary to screeningn the elderly in terms of depression in primary care. In the event of insufficiency by investigating the existing social support in the elderly, it may be useful to plan reinforcing measures.
\end{abstract}

Key Words: Elderly, social support, depression

\section{ÖZET}

Giriş: Geriatrik depresyon önemli bir halk sağlı̆̆1 sorunudur. Yaşlı bireyin algıladığı sosyal desteğin büyüklüğünün depresif belirtileri azalttığı bildirilmektedir. Bu çalışmanın amacı yaşı bireylerin algıladıkları sosyal desteğin geriatrik depresyon ile ilişkisini incelemektir. Yöntem: Kesitsel çalışmaya toplumda yaşayan 383 yaşlı dahil edilmiştir. Çalışma verileri araştırmacılar tarafından gerekli izinler alındıktan sonra yüz yüze görüşme tekniği ile toplanmıştır. Yatağa bağımlı, demans öyküsü olan ve antidepresan ilaç kullanan yaşlılar çalışma dışı tutulmuşlardır. Katılımcılara, katılımcının sosyodemografik, ekonomik ve sağlık durumu ile ilgili sorular yöneltilmiştir. Katılımcıların algıladıkları sosyal destek Çok Boyutlu Algılanan Sosyal Destek Ölçeği (ÇBASDÖ) ölçeği, depresyon durumları ise Geriatrik Depresyon Ölçeği (GDÖ) ile değerlendirilmiştir. Çalışma verileri SPSS 21.0 paket programı ile analiz edilmiştir. Bulgular: Katılımcıların \%52,2 $(\mathrm{n}=200)$ 'si kadınd1. Erkek katılımcıların yaş ortalaması 73,1 $\pm 6,2$ yıl; kadın katılımcıların ise 72,6 $\pm 6,4$ yıl idi. Katılımcıların ortalama

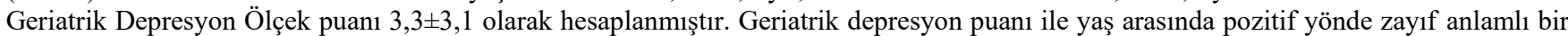
korelasyon mevcuttur $(\mathrm{R}=0,011 ; \mathrm{r}=0,108 ; \mathrm{p}=0,034)$. Cinsiyet açısından bakıldığında kadınlarda depresyon anlamlı olarak daha fazladır.

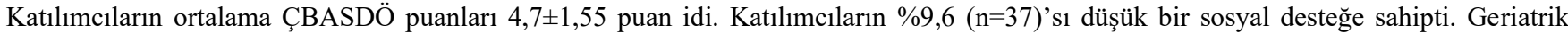
Depresyon ölçeği puanlarının her bir ÇBASDÖ ölçeği alt başlık puanları ile negatif yönde zayıf ve anlamlı korelasyonu mevcuttur. Çok Boyutlu Algılanan Sosyal Destek Ölçeğinin alt başlıkları ayrı ayrı ele alındığında her bir alt başlıkta algılanan sosyal destek arttıkça depresyon varlığı anlamlı olarak azalmaktadır (sırasıyla $\mathrm{p}=0,017 ; \mathrm{p}=0,003$ ve $\mathrm{p}=0,021$ ). Sonuç: Yaşlı bireylerde depresyon sıklığ hali hazırda yüksektir. Bu nedenle birinci basamakta yaşlıların depresyon açısından sorgulanması gereklidir. Depresif yaşlılarda mevcut sosyal desteğin araştırılarak yetersizlik olması durumunda güçlendirici önlemlerin planlanması faydalı olabilir.

Anahtar Kelimeler: Yaşlı, sosyal destek, depresyon

Received / Geliş tarihi: 16.10.2019, Accepted / Kabul tarihi: 23.03 .2020

${ }^{1}$ İstanbul Kartal Dr. Lütfi Kırdar Eğitim ve Araştırma Hastanesi Aile Hekimliği Kliniği

*Address for Correspondence / Yazışma Adresi: Aile Hekimliği Kliniği, İstanbul Kartal Dr. Lütfi Kırdar Eğitim ve Araştırma Hastanesi Kartal, İstanbulTÜRKIYE, E-mail: trcanoner@yahoo.com

Türkseven E, Öner C, Şimşek EE. The Relationship Between Geriatric Derpession and Perceived Social Support in Elderly: A Field Study. TJFMPC, 2020;14 (2): 203-209.

DOI: $10.21763 /$ tjfmpc. 633760 


\section{Gİiş̧}

Dünya nüfusunun hızlı bir biçimde yaşlanması önemli bir halk sağlığı problemidir. Türkiye'de yaşlı nüfus oranı her geçen gün artmaktadır. Ülkemizde 2000 yılında \%5,7 olan yaşlı nüfus oranı, 2010 y1lında \%7,2'ye; 2018 yllinda ise \%8,7'ye yükselmiştir. ${ }^{1}$ Artış trendi dikkate alındığında gelecek 10 yıllarda yaşlı sağlığı ile ilgili konuların ülkemizin temel sağlık konularından birisi olacağı düşünülebilir.

Yaşlilarda depresyon siklığı \%15-20 arasında değişmektedir. Yaşlılık döneminde birçok nedenin geriatrik depresyon sıklığını arttırdı ̆̆ bildirilmektedir. $\mathrm{Bu}$ nedenler arasında: düşük öz saygı, yalnızlık, ekonomik sıkıntılar, aile yapısının değişmesi, düşük sosyal destek, sevilen bir yakının kaybı, kadın olmak, dul olmak, düşük eğitim düzeyi, bilişsel bozukluklar, bakımevi/ huzurevinde kalmak, kişilik, beslenme yetersizliği, bedensel hastalıklar, fiziksel fonksiyon kaybı, bağımlılık, hastalıklarda kullanılan ilaçlar (antihipertansifler, Parkinson ilaçları vb), hastaneye yatmak sayılabilir., ${ }^{2,3}$ Erken tanı ile kişilerin günlük aktivitelerinde bağımlılık düzeyi azalmakta, yaşam kaliteleri yükselmektedir. ${ }^{4}$

Sosyal bir varlık olan insan için sosyal bağlar hayatın temelinde yer alır. Algılanan sosyal destek, kişinin sosyal destek ile alakalı gereksinimlerinin ne kadar karşılandığına dair inancı ifade etmektedir. ${ }^{5}$ Algılanan sosyal destek arttıkça bireylerin iyilik halleri artmakta, depresif bulguları azaltmakta, kronik hastalıkların kontrolü kolaylaşmakta ve mortalite düzeyleri düşmektedir. ${ }^{6,7}$

Yapılan güncel çalışmalar ister ailesi isterse kurumsal bir merkezden sosyal destek almış olsun, sosyal desteğin yaşlı bireylerde depresyon oranlarının azalttığını ve mental sağlığa belirgin olumlu etkisi olduğunu göstermektedir. ${ }^{8,9}$ Yaşlı bireylerin sosyal ağının büyüklüğünün depresif belirtileri azalttığ 1 ve yaşam doyumunu belirgin düzelttiği gösterilmiştir. ${ }^{10}$ Bireylerin algıladıkları sosyal destek yaş ile değişim gösterebilmektedir. Algılanan sosyal destekteki bu değişimlerin yaşlı bireylerdeki depresif bulguların farklılığında etkisi olduğu son yıllarda ileri sürülmektedir. ${ }^{11} \mathrm{Bu}$ çalışmanın amacı yaşıı bireylerin algıladıkları sosyal desteğin depresif belirtiler ile ilişkisini incelemektir.

\section{YÖNTEM}

Kesitsel tipteki çalışma 01.11.2018 - 30.01.2019 tarihleri arasında İstanbul ili Adalar ilçesinde yürütülmüştür. Çalışmaya alınacak asgari kişi toplumda yaşayan sayısı bilinen yaşlı evreninden $\% 95$ güven aralığı ve $\% 5$ hata payı ile hesaplanmış ve 337 kişi olarak bulunmuştur. Yaklaşık fire payı eklenerek çalışmaya 383 kişi alınmıştır. Örneklem için tabakalı örnekleme yolu seçilmiş ve örneklem oturulan bölge ve cinsiyete göre tabakalanmıştır. Çalışma için yerel etik kurul (Etik Kurul Tarih/No 31.10.2018-2018/514/140/14) ve kat1lımcilardan bilgilendirilmiş onam alınmıştır. Çalışma verileri araştırmacılar tarafından gerekli izinler alındıktan sonra yüz yüze görüşme tekniği ile toplanmıştır. Yatağa bağımlı, demans öyküsü olan ve antidepresan ilaç kullanan yaşlılar çalışma dış1 tutulmuşlardır.

Katılımcılara, katılımcinın sosyodemografik, ekonomik ve sağlık durumu ile ilgili sorular yöneltilmiştir. Katılımcıların algıladıkları sosyal destek Çok Boyutlu Algılanan Sosyal Destek Ölçeği (ÇBASDÖ) ölçeği ile depresif belirtileri ise Geriatrik Depresyon Ölçeği (GDÖ) ile değerlendirilmiştir.

ÇBASDÖ 1988 yılında Zimet ve arkadaşları tarafindan geliştirilen ve üç farklı kaynaktan alınan sosyal desteğin yeterliliğini değerlendirmeye yarayan kullanımı kolay ve kısa bir ölçektir. ${ }^{12}$. Ölçek aile, arkadaş ve özel bir insandan alınan desteği değerlendirmektedir. Ölçeğin güvenirliği yüksek olarak bulunmuştur $(\alpha=0,89)$. ÇBASDÖ 12 maddeden oluşan bir ölçektir. Her biri 4 maddeden oluşan desteğin kaynağına ilişkin 3 grup içerir. Bunlar; aile, arkadaş ve özel bir insandır. Ölçeğin Türkçe güvenirlik ve geçerliliği Eker ve Akar tarafından 1995 yılında yapılmıştır. ${ }^{13}$ Türkçe ölçeğin genel güvenirliği yeterli olarak bulunmuştur $(\alpha=0,73)$.

Geriatrik Depresyon Ölçeği- kısa form 15 sorudan oluşan ve 1991 yılında Burke ve arkadaşları tarafından geliştirilmiş bir ölçektir. ${ }^{14}$ Katılımcıya son bir hafta içindeki durumunu dikkate alarak cevaplaması istenen ve evet hayır şeklinde cevaplanan 15 soru yöneltilmektedir. Her bir sorunun vasfina göre 1 puan üzerinden puanlama yapılmakta ve toplam puan hesaplanmaktadir. 0-4 aras1 depresif bulgu yok, 5-8 aras1 hafif depresif bulgular, 9-11 orta düzeyde depresif bulgular ve 12 ve üstü puanlar şiddetli depresif bulgular olduğunu göstermektedir. Ölçeğin Türkçe güvenirlik ve geçerlilik çalışması Durmaz ve arkadaşları tarafından 2018 yılında yapılmıştır. ${ }^{15}$

Çalışma verileri SPSS 21.0 paket programı ile analiz edilmiştir. Çalışmada frekans, yüzde, siklık, ortalama, ortanca, minimum-maksimum değer, standart sapma gibi tanımlayıcı istatistikler, bivariable analizlerde Ki-kare testi uygulanmıştır. GDÖ, ÇBASDÖ’nün birbirleriyle olan ilişkileri, uygun korelasyon testleri ile incelenmiştir. 


\section{BULGULAR}

Çalışmaya toplumda yaşayan toplam 383 yaşlı dahil edilmiştir. Katılımcıların \%52,2 ( $\mathrm{n}=200)$ 'si kadındır. Erkeklerde yaş ortalaması 73,1 \pm 6,2 (65-90 yıl); kadınlarda $72,6 \quad \pm \quad 6,4$ y1l $\quad(65-99 \quad$ y1l $)$ idi. Katılımcıların sosyodemografik özellikleri Tablo 1'de derlenmiştir. Katılımcıların ortalama Geriatrik Depresyon Ölçek puanı 3,3 $\pm 3,1$ olarak hesaplanmıştır. Katılımcıların büyük çoğunluğunda depresif belirti yoktu $(\% 73,4 ; \mathrm{n}=281)$. Hafif depresif belirtileri olanların oranı $\% 17,0 \quad(n=65)$; orta düzeyde depresif belirtileri olanların oranı $\% 7,3$ $(n=28)$ ve şiddetli düzeyde depresif belirtisi olanların oranı ise $\% 2,3 \quad(\mathrm{n}=9)$ 'tür. Geriatrik depresyon puanı ile yaş arasında pozitif yönde zayıf anlamlı bir korelasyon mevcuttur $(\mathrm{R}=0,011$; $\mathrm{r}=0,108 ; \mathrm{p}=0,034)$. Cinsiyet açısından bakıldığında kadınlarda depresif belirtiler anlamlı olarak daha fazladır. Kadınların \%34,0 (n=68)'ünde depresif belirtiler varken bu oran erkeklerde \%18,6 $(n=34)$ 'dir $\quad\left(\chi^{2}=11,630 ; \quad \mathrm{p}=0,001\right) . \quad$ Depresif belirtilerin varlığı ve sosyal faktörlerle ilişkisi Tablo 2 de derlenmiştir. Katılımcıların GDÖ ortalama puanları 2 çocuğa kadar düşüş göstermekte ve bu düzeyden itibaren artmaktadır. $\quad\left(\chi^{2}=13,139\right.$; $\mathrm{p}=0,011)$.

Sağlığını iyi ve/veya çok iyi olarak tanımlayanların sadece \%10,6 (n=17)'sında depresif belirti mevcutken; sağlığını kötü ve/veya çok kötü tanımlayanlarda depresif belirti oranı \%46,7 $(n=14)$ 'dir $\quad\left(\chi^{2}=37,331 ; p<0,001\right)$. En az bir engelliliği olan katılımcılarda depresif belirti sıklığ $\% 42,2(n=38)$ iken, bu oran herhangi bir engelliliği olmayan kat1limcilarda \%21,8 (n=64)'dir $\left(\chi^{2}=14,634 ; p<0,001\right)$.

Katılımcıların ortalama ÇBASDÖ puanları 4,7 $\pm 1,55$ puan idi. Katılımcıların \%9,6 ( $\mathrm{n}=37)^{\prime}$ 's1 düşük bir sosyal desteğe sahipken, \%49,1 (n=188)'i orta düzeyde bir sosyal desteğe sahiptir. Yüksek düzeyde bir sosyal desteğe sahip olanların oranı ise \%41,3 (n=158)’tür. Geriatrik Depresyon Ölçeği puanları ile ÇBASDÖ toplam puanı arasında negatif yönde zayıf anlamlı bir korelasyon mevcuttur $(\mathrm{R}=$ $0,063 ; \mathrm{r}=-0,252 ; \mathrm{p}<0,001)$. Geriatrik Depresyon Ölçeği puanlarının her bir ÇBASDÖ ölçeği alt başlık puanları ile negatif yönde zayıf ve anlamlı korelasyon göstermektedir. Ölçeklerin birbirleri ile olan korelasyon verileri tablo 3'te derlenmiştir.

Katılımcıların depresyon varlığı ve algıladıkları sosyal destek arasındaki ilişkiler incelendiğinde algıladıkları sosyal destek düşük olanların \%32,4 (n=12)'ünde depresif belirtiler mevcutken, bu oran orta düzeyde sosyal destek alg1layanlarda \%33,5 $(n=63)$ ve yüksek düzeyde sosyal destek alg1layanlarda \%17,1 (n=27)'dir $\left(\chi^{2}=12,554 ; p=0,002\right)$. Çok boyutlu algılanan sosyal destek ölçeğinin alt başlıkları ayrı ayrı ele alındığında her bir alt başlıkta algılanan sosyal destek arttıkça ve depresif belirti varlığı anlamlı olarak azalmaktadir (sirasiyla $\mathrm{p}=0,017 ; \mathrm{p}=0,003$ ve $\mathrm{p}=0,021)$ (Tablo 4).

\begin{tabular}{|c|c|c|}
\hline \multicolumn{2}{|l|}{$\begin{array}{l}\text { Tablo 1: K } \\
\text { Değişken } \\
\end{array}$} & $\%,(n)$ \\
\hline \multirow{2}{*}{ Cinsiyet } & Erkek & $47,8(183)$ \\
\hline & Kadın & $52,2(200)$ \\
\hline \multicolumn{2}{|c|}{ Yaş ortalaması (yıl) } & $72,8 \pm 6,3$ \\
\hline \multirow{6}{*}{ Ĕ̆itim düzeyi } & Okuryazar değil & $11,7(45)$ \\
\hline & Okuryazar & $7,3(28)$ \\
\hline & 5 yıl (ilkokul) & $35,5(136)$ \\
\hline & 8 y1l (ortaokul) & $13,8(53)$ \\
\hline & $11 \mathrm{y} 1 \mathrm{l}$ ( lise) & $16,2(62)$ \\
\hline & $\geq 12$ y1l ( üniversite) & $15,4(59)$ \\
\hline \multirow{2}{*}{$\begin{array}{l}\text { Çalışma } \\
\text { durumu }\end{array}$} & Çalışıyor & $12,0(46)$ \\
\hline & Çalışmıyor & $88,0(337)$ \\
\hline \multirow{3}{*}{$\begin{array}{l}\text { Nerede } \\
\text { çalışıyor* }\end{array}$} & Kendi hesabına & $58,7(27)$ \\
\hline & İşçi & $30,4(14)$ \\
\hline & Kamu & $10,9(5)$ \\
\hline \multirow{2}{*}{ Sosyal güvence } & Var & $96,6(370)$ \\
\hline & Yok & $3,4(13)$ \\
\hline \multirow{4}{*}{ Medeni durum } & Evli & $54,0(207)$ \\
\hline & Dul & $33,9(130)$ \\
\hline & Boşanmış & $9,0(34)$ \\
\hline & Bekâr & $3,1(12)$ \\
\hline \multirow{3}{*}{$\begin{array}{l}\text { Aylık gelir } \\
\text { düzeyi }\end{array}$} & $<1500 \mathrm{TL}$ & $24,8(95)$ \\
\hline & $1501-3000$ & $54,1(207)$ \\
\hline & $>3001 \mathrm{TL}$ & $21,1(81)$ \\
\hline \multirow{5}{*}{ Çocuk Sayısı } & 0 & $8,6(33)$ \\
\hline & 1 & $12,5(48)$ \\
\hline & 2 & $39,4(151)$ \\
\hline & 3 & $20,1(77)$ \\
\hline & $4+$ & $19,4(74)$ \\
\hline \multirow{3}{*}{ İkamet Yeri } & Apartman dairesi & $58,8(225)$ \\
\hline & Müstakil ev & $34,7(133)$ \\
\hline & Diğer* & $6,5(25)$ \\
\hline \multirow{5}{*}{ Kim ile yaşııor } & Tek & $26,6(102)$ \\
\hline & Eşi & $52,5(201)$ \\
\hline & Çocukları & $16,7(64)$ \\
\hline & Diğer akrabaları & $3,2(12)$ \\
\hline & Diğer ** & $1(4)$ \\
\hline \multirow{4}{*}{$\begin{array}{l}\text { Hane halkı } \\
\text { büyüklüğü }\end{array}$} & 1 & $26,9(103)$ \\
\hline & 2 & 45,4 (174) \\
\hline & 3 & $15,9(61)$ \\
\hline & $>4$ & $11,8(45)$ \\
\hline \multirow{2}{*}{$\begin{array}{ll}\text { Kendine } & \text { ait } \\
\text { oda varlığı }\end{array}$} & Var & $92,7(355)$ \\
\hline & Yok & $7,3(28)$ \\
\hline
\end{tabular}




\begin{tabular}{|c|c|c|c|c|}
\hline & & $\begin{array}{c}\text { Depresyon yok } \\
\%, \text { (n) }\end{array}$ & $\begin{array}{c}\text { Depresyon var } \\
\%,(\mathrm{n})\end{array}$ & $\mathbf{p}$ \\
\hline \multirow{2}{*}{ Cinsiyet* } & Erkek & $81,4(149)$ & $18,6(34)$ & \multirow{2}{*}{0,001} \\
\hline & Kadın & $66,0(132)$ & $34,0(68)$ & \\
\hline \multicolumn{2}{|l|}{ Yaş ortalaması* } & $72,7 \pm 6,3$ & $73,4 \pm 6,7$ & $0,444 * *$ \\
\hline \multirow{2}{*}{ Yaş* } & $65-74$ & $74,3(185)$ & $25,7(64)$ & \multirow{2}{*}{0,575} \\
\hline & $\geq 75$ & $71,6(96)$ & $28,4(38)$ & \\
\hline \multirow{3}{*}{ Eğitim* } & Okuryazar değil & $44,4(20)$ & $55,6(25)$ & \multirow{3}{*}{$<0,001$} \\
\hline & İlkokul ve altı & $68,9(113)$ & $31,1(51)$ & \\
\hline & Ortaokul ve üstü & $85,1(148)$ & $14,9(26)$ & \\
\hline \multirow{3}{*}{ İkamet* } & Müstakil ev & $74,4(99)$ & $25,6(34)$ & \multirow{3}{*}{0,294} \\
\hline & Apartman dairesi & $74,2(167)$ & $25,8(58)$ & \\
\hline & Diğer & $60,0(15)$ & $40,0(10)$ & \\
\hline \multirow{2}{*}{ Oda varlığı* } & Var & $74,1(263)$ & $25,9(92)$ & \multirow{2}{*}{0,259} \\
\hline & Yok & $64,3(18)$ & $35,7(10)$ & \\
\hline \multirow{5}{*}{ Kiminle yaşıyor } & Tek & $73,5(75)$ & $26,5(27)$ & \multirow{5}{*}{0,082} \\
\hline & Eşiyle & $77,6(156)$ & $22,4(45)$ & \\
\hline & Çocuklarıyla & $59,4(38)$ & $40,6(26)$ & \\
\hline & Diğer akraba & $75,0(9)$ & $25,0(3)$ & \\
\hline & Diğer & $75,0(3)$ & $25,0(1)$ & \\
\hline \multirow{4}{*}{ Medeni durum } & Evli & $77,3(160)$ & $22,7(47)$ & \multirow{4}{*}{0,093} \\
\hline & Bekâr & $58,3(7)$ & $41,7(5)$ & \\
\hline & Dul & $66,9(87)$ & $33,1(43)$ & \\
\hline & Boşanmış & $79,4(27)$ & $20,6(7)$ & \\
\hline \multirow{3}{*}{ Hane halkı büyüklüğü } & 1 & $73,8(76)$ & $26,2(27)$ & \multirow{3}{*}{0,293} \\
\hline & 2 & $76,4(133)$ & $23,6(41)$ & \\
\hline & $3+$ & $67,9(72)$ & $32,1(34)$ & \\
\hline \multirow{3}{*}{ Gelir* } & $\leq 1500 \mathrm{TL}$ & $58,9(56)$ & $41,1(39)$ & \multirow{3}{*}{$<0,001$} \\
\hline & $1501-3000 \mathrm{TL}$ & $74,9(155)$ & $25,1(52)$ & \\
\hline & $\geq 3000 \mathrm{TL}$ & $86,4(70)$ & $13,6(11)$ & \\
\hline \multirow{2}{*}{ Çalışma durumu } & Evet & $73,3(247)$ & $26,7(90)$ & \multirow{2}{*}{0,290} \\
\hline & Hayır & $73,9(34)$ & $26,1(12)$ & \\
\hline \multirow{2}{*}{ Sosyal güvence } & Evet & $73,2(271)$ & $26,8(99)$ & \multirow{2}{*}{1,000} \\
\hline & Hayır & $76,9(10)$ & $23,1(3)$ & \\
\hline \multirow{2}{*}{ Kronik hastalık varlığı } & Hayır & $84,6(44)$ & $15,4(8)$ & \multirow{2}{*}{0,048} \\
\hline & Evet & $71,6(237)$ & $28,4(94)$ & \\
\hline
\end{tabular}

* Satır yüzdesi verilmiştir. ** Mann- Whitney U testi ile analiz edilmiştir.

\begin{tabular}{|c|c|c|c|c|c|}
\hline \multicolumn{2}{|c|}{ Tablo 3. ÇBASDÖ toplam puanı, alt basslık puanları ve GDÖ puanları arasındaki ilişki. } \\
\hline & $\begin{array}{c}\text { ÇBASDÖ } \\
\text { Toplam puan } \\
(\mathbf{r}, \mathbf{p})\end{array}$ & $\begin{array}{c}\text { ÇBASDÖ } \\
\text { Özel insan } \\
\text { puanı } \\
(\mathbf{r}, \mathbf{p})\end{array}$ & $\begin{array}{c}\text { ÇBASDÖ } \\
\text { Aile puanı } \\
(\mathbf{r}, \mathbf{p})\end{array}$ & $\begin{array}{c}\text { ÇBASDÖ } \\
\text { Arkadaş puanı } \\
(\mathbf{r}, \mathbf{p})\end{array}$ & $\begin{array}{c}\text { GDÖ puanı } \\
(\mathbf{r}, \mathbf{p})\end{array}$ \\
\hline \multirow{2}{*}{ GDÖ puanı* } & $-0,252$ & $-0,145$ & $-0,221$ & $-0,193$ & 1 \\
\hline
\end{tabular}

*Spearman korelasyonu kullanılmıştır 


\begin{tabular}{|c|c|c|c|c|}
\hline & & $\begin{array}{c}\text { Depresyon yok } \\
\%,(n)\end{array}$ & $\begin{array}{c}\text { Depresyon var } \\
\%,(n)\end{array}$ & $\mathbf{P}^{*}$ \\
\hline \multirow{3}{*}{ ÇBASDÖ toplam } & Düşük & $67,6(5)$ & $32,4(12)$ & \multirow{3}{*}{0,002} \\
\hline & Orta & $66,5(125)$ & $33,5(63)$ & \\
\hline & Yüksek & $82,9(131)$ & $17,1(27)$ & \\
\hline \multirow{3}{*}{ Özel insan alt başlığı } & Düşük & $70,1(101)$ & $29,9(43)$ & \multirow{3}{*}{0,017} \\
\hline & Orta & $66,0(62)$ & $34,0(32)$ & \\
\hline & Yüksek & $81,4(108)$ & $18,6(27)$ & \\
\hline \multirow{3}{*}{ Aile alt başlığı } & Düşük & $59,5(22)$ & $40,5(15)$ & \multirow{3}{*}{0,003} \\
\hline & Orta & $56,4(22)$ & $43,6(17)$ & \\
\hline & Yüksek & $77,2(237)$ & $22,8(70)$ & \\
\hline \multirow{3}{*}{ Arkadaş alt başlığ } & Düşük & $64,9(87)$ & $35,1(47)$ & \multirow{3}{*}{0,021} \\
\hline & Orta & $76,1(67)$ & $23,9(21)$ & \\
\hline & Yüksek & $78,9(127)$ & $21,1(34)$ & \\
\hline
\end{tabular}

* Ki-kare testi kullanılmıştır.

\section{TARTIŞMA}

Çalışma sonucunda yaşlıların algıladıkları sosyal desteğin depresif belirti gösterme oranları ile anlamlı ilişki gösterdiği görülmüştür. Algıladıkları sosyal destek yüksek olan yaşlılarda, algıladıkları sosyal destek yetersiz olanlara oranla daha az depresif belirti görülmektedir. $\mathrm{Bu}$ durum sosyal desteğin algılandığı kaynağa göre değişiklik göstermemektedir.

Depresyon yaşl1lık döneminde sık görülen bir psikiyatrik rahatsızlıktır. Yapılan ulusal çalışmalarda depresif belirti görülen yaşlı oranları \%23-37 arasında bildirilmektedir. ${ }^{16}$ Kadın cinsiyet, düşük sosyoekonomik düzey, yalnız yaşamak, dul olmak, kronik hastalık varlığı yaşlılarda depresyon sıklığını arttırmaktadır. ${ }^{17,18}$ Çalışmamızda yaşlı bireylerde depresif belirti gösterme sıklığı \%26,6 olarak bulunmuştur. Çalışmamızın bulguları ulusal literatürle uyumlu görünmektedir. Öte yandan çalışmamızda depresif belirti görülme ile kadın cinsiyet olma, düşük eğitim düzeyine sahip olma, düşük gelir seviyesi, çocuk sayısı ve kronik hastalığa sahip olma ile anlamlı ilişki gösterdiği belirlenmiştir. $\mathrm{Bu}$ bulgular ulusal ve uluslararası literatür ile uyumludur. Diğer sosyal belirleyicilerle (yaşadığ konut, kiminle yaşadığı, medeni durumu ve hane halkı büyüklüğü vb.) ilişki gösterilememiştir. $\mathrm{Bu}$ farklılığın nedeninin çalışmanın yapıldı ̆̆ 1 yerin sosyal özelliklerinden kaynaklandığı düşünülmektedir. Çalışmanın yapıldığı alan daha izole, yaşlı nüfusun fazla olduğu, ekonomik ve eğitim düzeyinin daha yüksek olduğu bir bölgedir.

Çalışmamızda GDÖ ortalama puanlarının 2 çocuğa kadar düşüş gösterdiği ve bu düzeyden artarak 4 ve üstü çocuğu olanlarda en yüksek düzeye çıktığı saptanmıştır. Yapılan çalışmalar çocuk sayısı azaldıkça GDÖ puanlarının da azaldığını bildirmektedir. ${ }^{19}$ Yaşlı bireylerin çocukları olmaması durumunda bu çocuklarla ilişkili gelecek beklentilerinin olmaması, çok çocuklu yaşlılarda ise beklentilerin karşılanmamış olması bu farklılığın temel nedeni olabilir. ${ }^{20} \mathrm{Bu}$ sonuç yorumlanırken de çalışma alanının sosyal özelliklerinin dikkate alınması gereklidir.

Yapılan çalışmada GDÖ puanları ile ÇBASDÖ toplam puanı ve ölçeğin alt başlıkları arasında negatif yönde zayıf anlamlı bir korelasyon belirlenmiştir. Katılımcıların depresyon varlığı, algıladıkları sosyal destek arttıkça azalmaktadır. Bu durum tüm alt başlıklar için de geçerlidir. Ulusal bir çalışmada depresyonu olan hastaların algıladıkları sosyal destek arttıkça, depresyonun azaldığını bildirilmiştir. Bizim çalışmamızdaki bulgularla uyumlu şekilde olan bu çalışmada da sosyal desteğin özel bir insan, arkadaş veya aileden alınması durumunda farklılık olmadığı gösterilmiştir. ${ }^{21}$ Yine farklı çalışmalarda sosyal desteği fazla olanların depresyon düzeylerinin düşük olduğu, daha az yalnızlık yaşadıkları, desteği daha az olanlara göre yaşamlarından daha fazla memnun olduklarını bildirilmektedir. ${ }^{22}$

Yapılan bir başka çalışmada da benzer şekilde sosyal destek ile depresyon arasında istatistiksel olarak negatif anlamlı bir ilişki belirlenmiştir. ${ }^{23}$ Sosyal desteği yetersiz bireylerin depresyon risklerinin arttığ $\breve{b}_{1}$ bildirilmektedir. Öte yandan verilen sosyal desteğin miktarı ve özelliğinden çok, hastanın desteğin ne kadarını hissettiği anahtar rol oynamaktadır. ${ }^{24}$

Yaşlı bireylerde depresyon sıklığ yüksektir. $\mathrm{Bu}$ durum bireyin yaşlılık sürecine 
uyumunu güçleştirmekte, genel sağlığını bozmakta ve tıbbi durumların daha abartılı olarak algilanmasına neden olabilmektedir. Bu nedenle aile hekimi tarafından tüm yaşlıların, bu mümkün değilse risk faktörlerini içerenlerin, depresyon açısından sorgulanması gereklidir. Depresif yaşlılarda mevcut sosyal desteğin, sosyal ağ büyüklüğünün ve bireyin algıladığı sosyal desteğin araştırılarak yetersizlik olması durumunda güçlendirici önlemlerin bir sosyal çalışmacı ile birlikte planlanması faydalı olabilir.

Araştırma sonuçları dikkate alındığında, algılanan sosyal desteğin özellikle arkadaş ve özel insan alt başliklarında daha düşük olduğu gerçeğinden hareketle yaşlıların algıladıkları sosyal desteği arttırmak için sosyal yalnızlık durumlarının azaltılması gereklidir. Sosyal yalnızlıkla etkin mücadele edilebilmesi için ise akranlarla etkin iletişim kurulması, onlarla sık bir araya gelinmesi önerilmektedir. Yaşı bireylerin yaşla beraber aile üyesi sayısı artarken arkadaş, komşu sayıları aynı kalmakta veya azalmaktadır. Bu amaçla kamu ya da sivil toplum örgütleri tarafından yaşlıların aylık toplant1, yemek veya gezi gibi sosyal aktivitelere dâhil edildiği toplum temelli hizmetlerin arttırılması, yaşlı yaşam evleri ve gündüz bakımevleri kurulması faydalı olabilir.

\section{KAYNAKLAR}

1. TÜİK, Adrese dayalı nüfus kayıt sistemi sonuçları 2018

2. Balcı E, Şenol V, Eşel E, Günay O, Elmalı F. 65 yaş ve üzeri bireylerin depresyon ve malnutrisyon durumları arasındaki ilişki. Türkiye Halk Sağlığı Dergisi 2012; 10(1): 3743.

3. T.C. Sağlık Bakanlığı. Yaşlı Sağlığı Modülleri(Eğitimciler için Eğitim Rehberi). Ankara,2011: 276-277

4. Hacıhasanoğlu R, Türkleş S. Depression and affecting factors in the old at theage of 65 and over. Atatürk Üniversitesi Hemşirelik Yüksekokulu Dergisi 2008; 11(2): 55-60.

5. Procidano ME, Heller K. Measured of Perceived Social Support From Friends and Familiy: Three Validation Studies. Am J Community Psychol 1983;11(1): 1-25.

6. Bartolini S, Bilancini E, Pugno M. Did the decline in social connections depress Americans' happiness? Soc Indic Res 2013;110:1033-59.

7. Nieminen T, Prättälä R, Martelin T, Harkanen T,Hyyppa MT, Alanen E, et al. Social capital, health behaviours and health: a populationbased associational study. BMC Public Health 2013;13:613.

8. Chou KL. Combined effect of vision and hearing impairment on depression in older adults: evidence from the English Longitudinal
Study of Ageing. J Affect Disord 2008; 106: 191-196.

9. Carpenter BD. Family, peer, and staff social support in nursing home patients: contributions to psychological well-being. J App. Gerontol 2002; 21: 275-293.

10. Sylvia YCL K, Dannii YL Y, Annie C. The Moderating role of perceived social support on the relationship between physical functional impairment and depressive symptoms among Chinese nursing home elderly in Hong Kong. Scientific World Journal 2011; 11: 1017-1026.

11. Melchiorre MG, Chiatti C, Lamura G, TorresGonzales F, Stankunas M, Lindert J, et al. Social support, socio-economic status, health and abuse among older people in seven European countries. PloS One 2013;8(1):e54856.

12. Zimet GD, Dahlem NW, Zimet SG, Frley GK. The multidimentional scale of percived social support. J Pers Assess 1998; 52(1): 30-41.

13. Eker D, Arkar H. Çok boyutlu algılanan sosyal destek ölçeğinin faktör yapısı, geçerlilik ve güvenirliği. Türk Psikoloji Dergisi 2001;12 (1): 17-25.

14. Burke WJ, Roccaforte WH, Wengel SP. The short form of the Geriatric Depression Scale: a comparison with the 30-item form. J Geriatr Psychiatry Neurol 1991; 4(3): 173-178.

15. Durmaz B, Soysal P, Ellidokuz H, Isik AT. Validity and reliability of geriatric depression scale-15 (short form) in Turkish older adults. North Clin Istanb 2018 ;5(3): 216-220.

16. Arslantaş H, Ergin F. 50-65 yaş arasındaki bireylerde yalnızlık, depresyon, sosyal destek ve etki eden faktörler. Turkish Journal of Geriatrics 2011; 14 (2): 135-144.

17. World Health Organization. World report on Ageing and Health 2015. p 57-58

18. Maral I, Aslan S, İlhan MN, Yildırım A, Candansayar S, Bumin A. Depresyon yaygınlığı ve risk etkenleri: Huzurevinde ve evde yaşayan yaşlılarda karşılaştırmalı bir çalışma. Türk Psikiyatri Dergisi 2001;12(4):251-259.

19. Bingöl G, Demir A, Karabek R, Kepenek B, Yıldırım N, Kaytaz EG. Bazı değişkenler açısından 65 yaş üstü bireylerin depresyon düzeylerinin incelenmesi. Göztepe Tıp Dergisi 2010; 25(4):169-176.

20. Demet MM, Taşkın OE, Deniz F, Karaca N, İçelli İ. Manisa Huzurevlerinde Kalan Yaşlılarda Depresyon Belirtilerinin Yaygınlığı ve İlişki Risk Etkenleri, Türk Psikiyatri Dergisi, 2002;13(4):290-299.

21. Mersin S, Arslan F. Depresyonlu hastaların sosyal destek algıları. Uluslararası Sosyal Araştırmalar Dergisi 2018;11(56): 403-410

22. Kahn JH, Hessling RM, Russell DW. Social support, health, and well-being among the elderly: What is the role of negative affectivity? 
Personality and Individual Differences 2003; 35(1):5-17.

23. Aksüllü N, Doğan S. Huzurevinde ve evde yaşayan yaşlılarda algılanan sosyal destek etkenleri ile depresyon arasındaki ilişki. Anatolian Journal of Psychiatry 2004;5:76-84.

24. McDougall MA, Walsh MW, Kristina KR, Miller L, Stevermer M, Fogas BS. The effect of social networking sites on the relationship between perceived social support and depression. Psychiatry Research 2016;246:223229. 